\title{
REFLEXÓPOLIS. CAMINATA POR LAS CIUDADES \\ DE WOODY ALLEN
}

REFLEXOPOLIS. WALK THROUGH WOODY ALLEN'S CITIES

MARLEN MENDOZA VILLARREAL*

\section{R E S U M E N}

El presente artículo reflexiona sobre la importancia de las locaciones para transmitir los valores sociales, culturales y políticos del contexto que el cine quiere recrear. Después de haber analizado el uso de las locaciones en el cine de Woody Allen, se esgrimen una serie de autores latinoamericanos que han sabido captar la compleja realidad de las ciudades del hemisferio sur.

PALABRAS CLAVE: Woody Allen, locaciones, espacio tácito, ciudad latinoamericana.

\section{A B S T R A C T}

The present article reflects on the importance of the locations to transmit the social, cultural and political values of the context that the cinema wants to recreate. After having analyzed the use of locations in Woody Allen's cinema, we wield a series of Latin American authors who have managed to capture the complex reality of the cities of the southern hemisphere.

KEYWORDS: Locations, tacit space, Latin American city. 


\section{INTRODUCCIÓN}

Usualmente hablar de la relación entre arquitectura y cine, remite únicamente a escenarios y locaciones. Pocas veces se repara en identificar aquello que un lugar le imprime a la narrativa. Es frecuente que, como arquitecta, cada ámbito lo relacione estrechamente con ella y me parece intrínseca a todo el quehacer humano; no se puede concebir una disciplina más humanista que la arquitectura; $\mathrm{y}$ el cine, al ser una ventana para el descubrimiento y exploración personal, se acerca a una suerte de escaparate de ideas y un receptáculo de cuestionamientos y teorías. Juntos figuran como la pareja perfecta.

Hablar de cine y arquitectura desemboca en infinidad de posibilidades y posturas; pueden ser culturales, psicológicas y sociales. Además del cine de autor de fuerte influencia, hay muchas, ahora con la cada vez más mencionada disciplina de diseño de producción, el director tiene la facilidad de encargar su visión a un departamento de arte y es maravilloso saber que también se les puede premiar. Se sabe que es un trabajo arduo y meticuloso: el arte de sentir en un lugar.

\section{EL LUGAR ES TAN IMPORTANTE COMO EL ARGUMENTO EN SÍ MISMO}

En la mayoría de las películas la locación es fundamental, quién podría concebir Midnight in Paris (Woody Allen, 2011) sin aquella deriva noctámbula de Gil (Owen Wilson) a través de la Ciudad Luz, enamorado de un estilo de vida y de una ciudad, con el fabuloso guion de Allen quien parodia el círculo infernal de las vacaciones familiares; que no son exclusivas de los grupos grandes, sino también de los viajes en pareja, llevando al extremo los límites de convivencia y la pérdida de la intimidad, del espacio propio.

\section{FIGURA 1. CARTEL DE MIDNIGHT IN PARIS (2011), DE WOODY ALLEN}

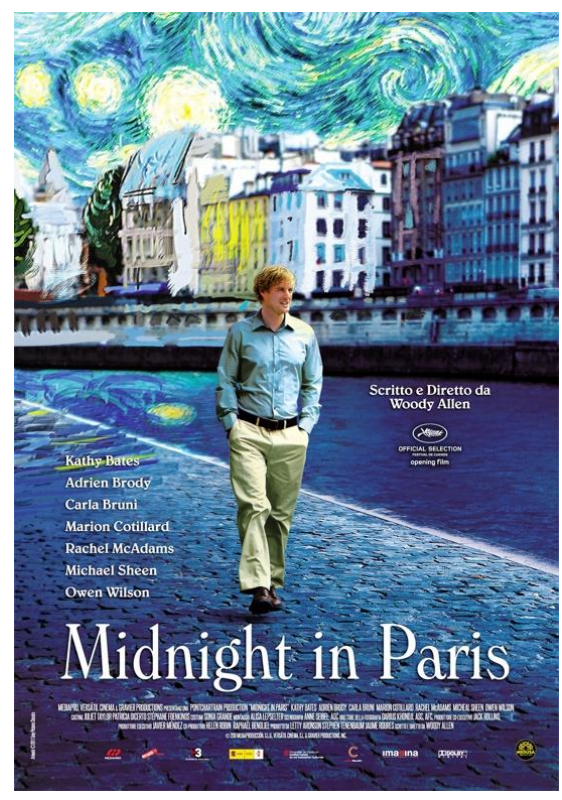

Fuente: Fotograma Cartel de Midnight in Paris. 
Para Allen es recurrente el debate interior y el dialogo exterior, es decir, sus personajes son abstractos con sus ideas y suelen desatar una verborrea con intención de explicar y explicarse los fenómenos en los que están involucrados, casi siempre de tintes morales e intelectuales.

El lugar cobra así distintas capas, por un lado, el espacio tácito de las locaciones en contraparte con el lugar interior de cada personaje, el compartido durante los diálogos en el acto de externar ideas y, por último, el lugar que funge como vínculo entre el espectador y la pantalla.

\section{CAMINAR COMO UN ACTO SUBVERSIVO Y DE REFLEXIÓN}

No es una particularidad que la filmografía de Woody Allen abra espacio para el ancestral acto de caminar, las icónicas fotografías de sus cintas generalmente refieren a largas charlas entre personajes a través de la ciudad, mientras deambulan por la calle, entran a una librería, pasan por un café o compran algo en algún mercado local.

FIGURA 2. ESCENA DE MIDNIGHT IN PARIS, DONDE LOS PROTAGONISTAS CAMINAN POR LA CIUDAD

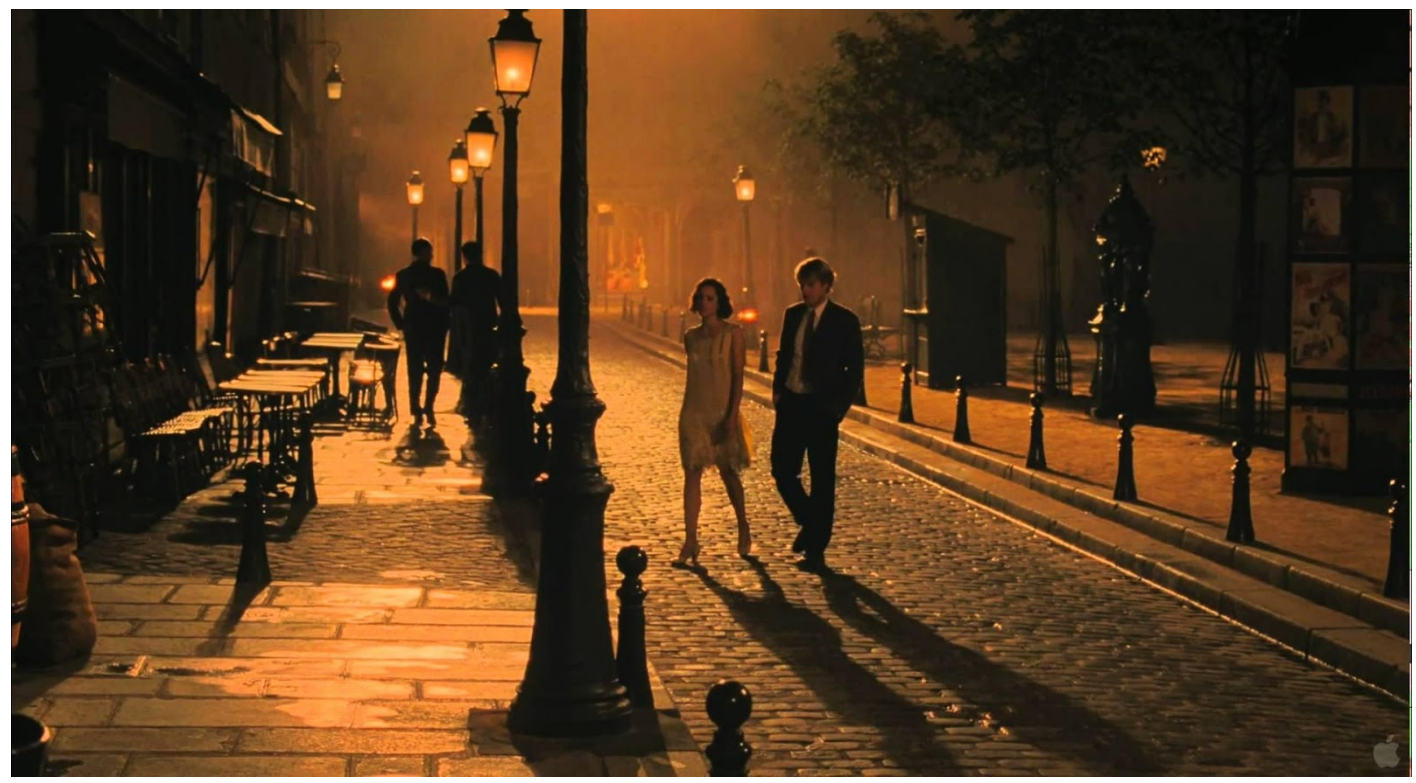

Fuente: Fotograma Midnight in Paris.

Allen imprime carácter y localidad haciéndolos caminar, imágenes que llegan a nuestra mente solo con recordar
Manhattan (1979) y esa icónica e inolvidable toma con vista al puente, las incansables charlas entre Annie Hall (Diane Keaton) y Alvy Singer (Woody 
Allen) en Annie Hall (1977) o mientras se ve enloquecer a Roy (Josh Brolin) cuando camina junto a Dia (Freida Pinto) por el Londres contemporáneo.

Figura 3. Escena de Manhattan (1979)

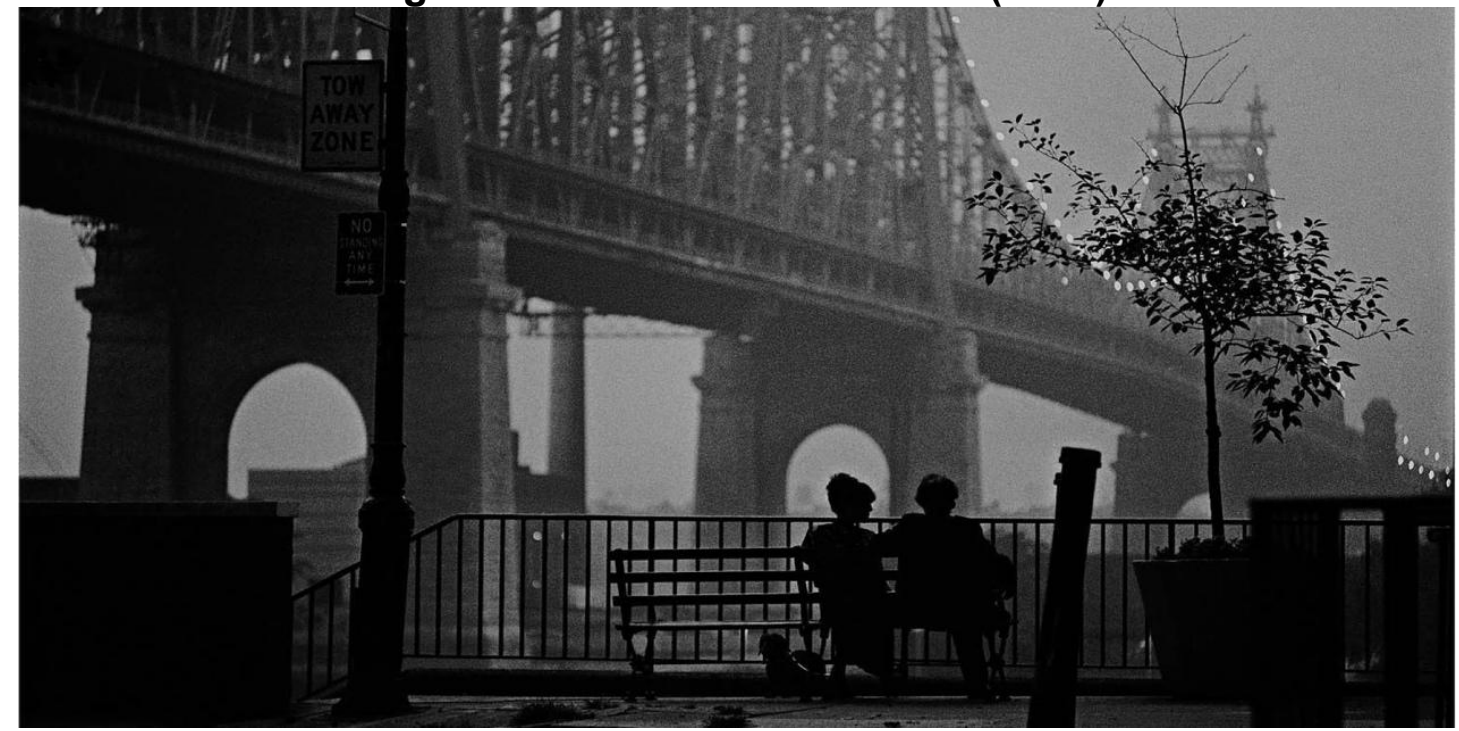

Fuente: Fotograma Manhattan.

Caminar también significa perderse cómo se puede ver en To Rome With Love (2012) con Milly (Alessandra
Mastronardi), cuando pide indicaciones y termina desconcertada por lascontradicciones que recibe de los lugareños.

FIGURA 4. ESCENA DE TO ROME WITH LOVE, CON ALESSANDRA MASTRONARDI EN LA PIAZZA DEL POPOLO

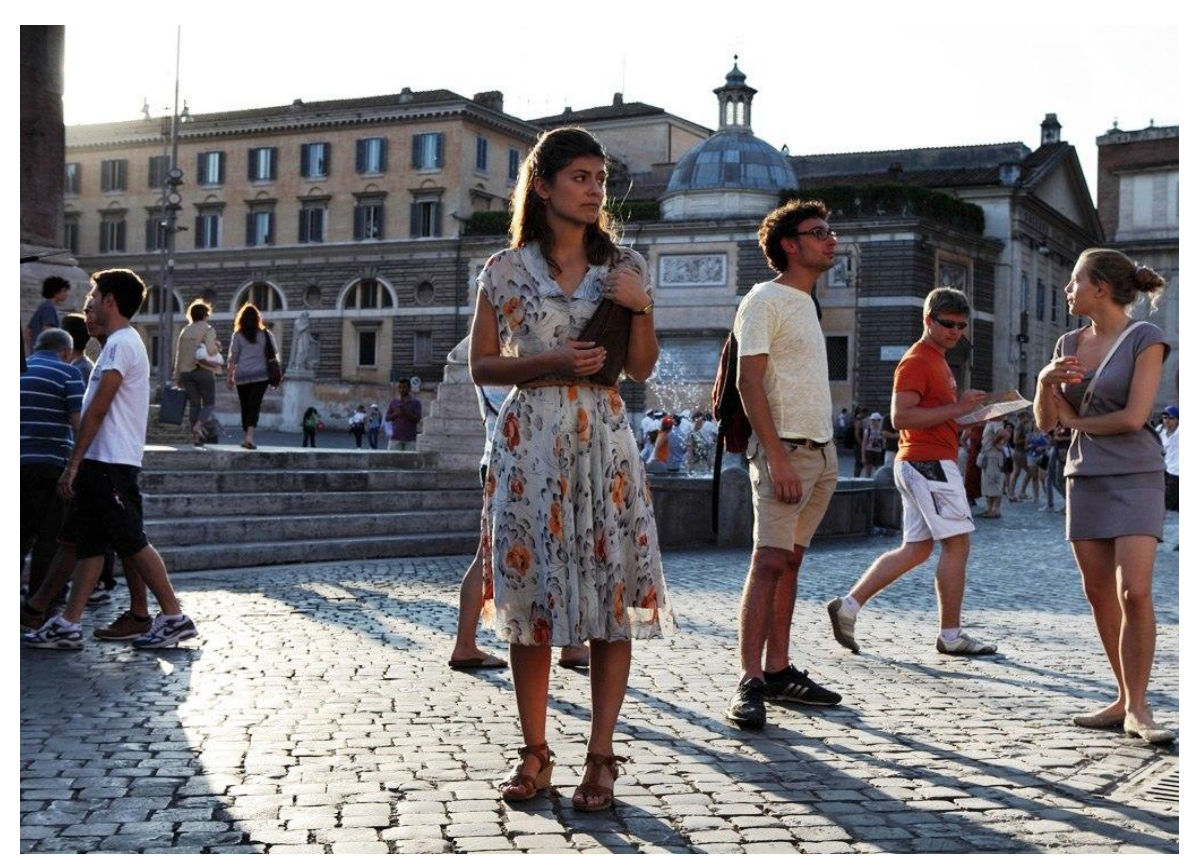

Fuente: Fotograma To Rome with Love. 


\section{CIUDADES QUE INVITAN A LA IMAGINACIÓN}

A través de los años las ciudades han adquirido la reputación de entes voraces y desalmados, máquinas de habitar con ritmos acelerados, falta de conexión interpersonal, indiferencia y toneladas de polución y basura; en resumen, se les considera como una especie de enfermedad corrosiva. Al contrario de lo que se pensaba por ejemplo en la antigua Grecia o en el mundo Mesoamericano, donde las ciudades eran lugares exclusivos para señores o sacerdotes que estarían en contacto directo con las deidades.

La ciudad era considerada un espacio privilegiado que, ante la intromisión de algún no grato, podría repercutir en algún sacrificio o pena de muerte, recordando quizás la Ciudad Prohibida en Pekín, China. En la ciudad se erigían templos y edificios para los gobernantes, ya fuera que vivieran ahí con su familia o que hicieran visitas ocasionales, contando con un apéndice con vistas y ubicación privilegiada cercano al templo. Las parcelas eran cuidadosamente seccionadas y distribuidas, en muchas ocasiones como en el caso de los Mayas, en función de los puntos cardinales o de eventos astronómicos. Los edificios y templos eran recintos sumamente valorados que incluso servían para medir el tiempo o cambios climatológicos. En la cultura egipcia aquellos afortunados que podía estudiar o aprender a escribir iban a las ciudades para enlistarse y recluirse. Es así como la ciudad fungía como un centro de operaciones políticas, científicas y espirituales.

Al transcurrir de los años, la urbe se ha transformado siempre alimentada por los movimientos sociales y la tecnología hasta llegar a lo que se conoce hoy en día. Pero no es de extrañar que las ciudades más icónicas a nivel mundial sean objeto de intriga y misterio y que inspiren a imaginar historias que puedan suceder dentro de ellas. Woody Allen, en los últimos años de su trabajo, como director y guionista, ha dedicado sus cintas a grandes, conflictivas y neuróticas ciudades. Es un apasionado de las imperfecciones y de esnobismo cultural, característico de espacios multiculturales... Roma, Londres, Barcelona, Paris, Nueva York (más de una vez) y Los Ángeles, son algunas de las ciudades predilectas del director, siempre imprimiendo particularidades a los personajes que albergan. 


\section{LA OTREDAD DE LAS DIFERENCIAS URBANAS}

La obra de Woody Allen es un camino similar a una montaña rusa. Sin embargo, hay un aspecto importante que no se ha podido aún mirar en su trabajo: mirar a las ciudades latinoamericanas. Mucho y valioso trabajo se realiza por parte de los directores, guionistas y escritores latinoamericanos por llevar las problemáticas urbanas latinoamericanas al cine internacional, para ello se tiene la vertiginosa Güeros (México, 2014), que hace un "road trip" urbano a través de la Ciudad de México.

FIGURA 5. CARTEL DE GÜEROS (2014), DE DE ALONSO RUIZPALACIOS

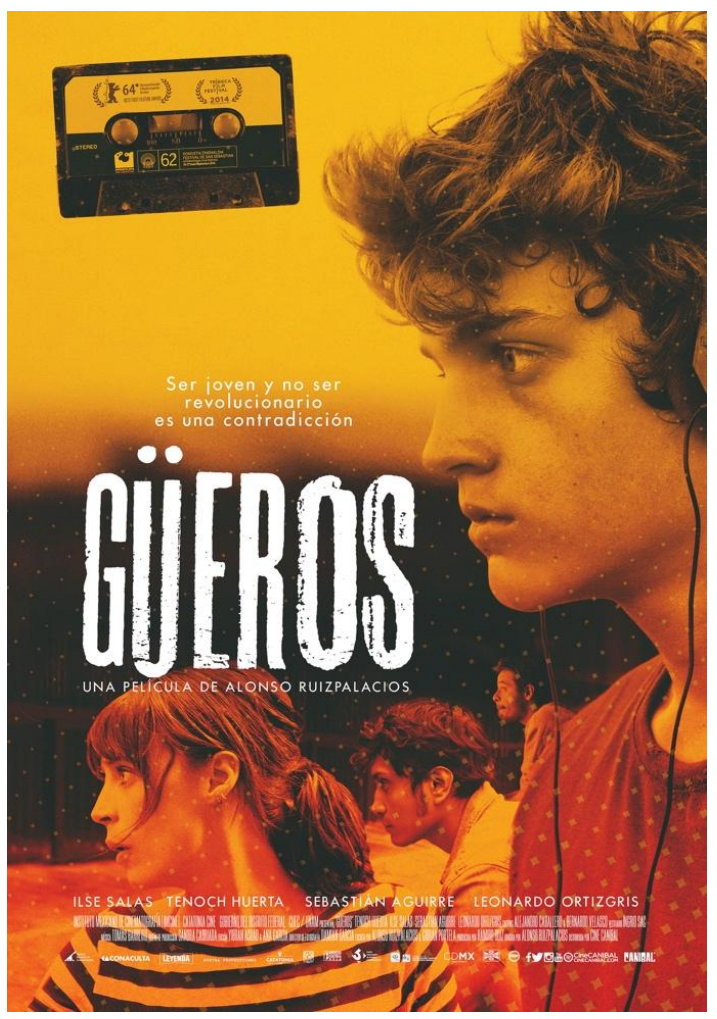

Fuente: Fotograma Cartel de Güeros.
La inolvidable comedia romántica $\mathrm{Me}$ dianeras (Argentina, 2011), donde presenta una historia amorosa en un barrio altamente poblado en la ciudad de Buenos Aires:

FIGURA 6. CARTEL DE MEDIANERAS (2011), DE GUSTAVO TARETTO

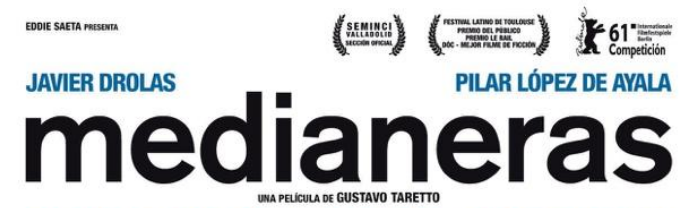
BUENOS AIRES EN LA ERA DEL AMOR VIRTUAL

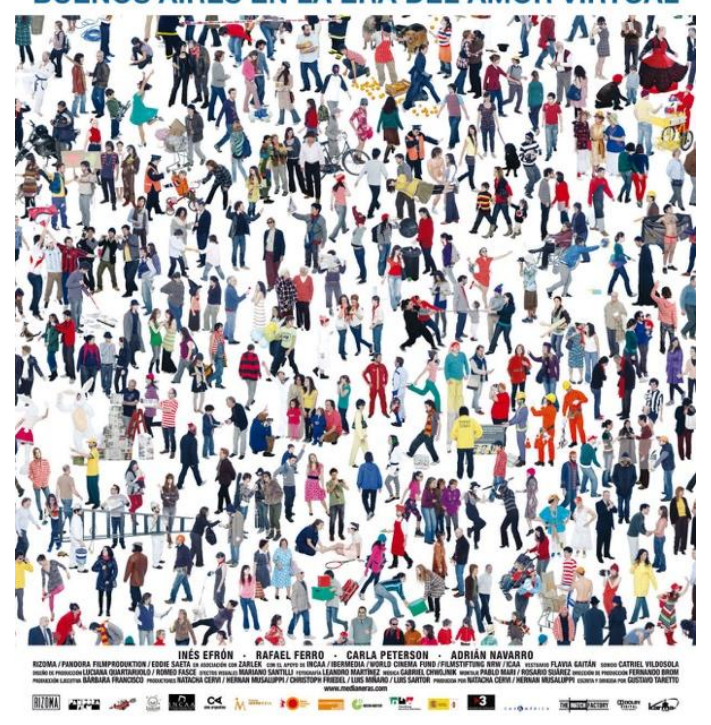

Fuente: Fotograma Cartel de Medianeras.

O Aquarius (Brasil, 2016), que retrata una pelea feroz entre Clara (una implacable Sônia Braga) dueña de un departamento en el barrio de Boa Viagem y la inmobiliaria que busca sacarla de él. 


\section{FIGURA 7. AQUARIUS (2016) DE KLEBER MENDONÇA FILHO}

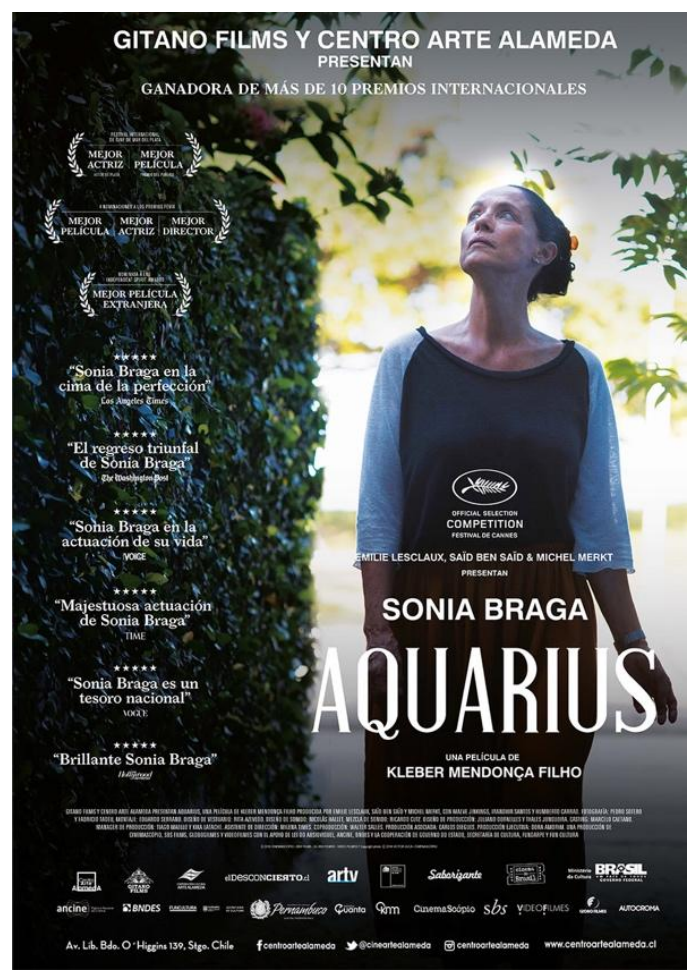

Fuente: Fotograma Aquarius.

Las anteriores son magníficos estudios sobre la realidad urbana de cada ciudad e invitan a la reflexión del espacio.

Es de suma importancia conocer y comparar los esquemas en la cosmogonía del planteamiento de los escenarios que constituyen una pieza cinematográfica; siempre dicen mucho sobre el autor y su visión respecto al modelo que planean exhibir; es decir, cada película permite a las personas ponerse en los zapatos de su creador y mirar a través de sus ojos cómo es que han vivido o estudiado y cómo le afectaron esos espacios, desde el ruido ambiental, la luz, las calles y las personas que ahí la transitan, es sin lugar a dudas el mejor escaparate, una probeta de experimento social, cultural y arquitectónico. Todo desde la comodidad de un asiento.

\section{PARA CITAR ESTE ARTÍCULO:}

Mendoza, M. (2018). Reflexópolis. Caminata por la ciudades de Woody Allen. Collectivus, Revista de Ciencias Sociales, 5(1), 92-98.

DOI: http://dx.doi.org/10.15648/Coll.1.2018.7

Recibido: 6/11/2017 Aprobado: 9/12/2017 